\title{
Uzun kemik diyafizer metastazları
}

\section{Diaphyseal metastases of long bones of the extremities}

\author{
Kerem Başarır, Mustafa Onur Karaca
}

Ankara Üniversitesi Tıp Fakültesi Ortopedi ve Travmatoloji Kliniği, Ankara

\begin{abstract}
Meme, akciğer ve prostat gibi birçok kanserin uzak bölge nükslerinin sık görülen yerleşimlerinden birisi kemik dokusudur. Habis bir tümörün kemiğe metastaz yapması halinde, hastada beklenen yaşam süresi kısalmaktadır. Metastatik lezyonlar en sık vertebrada $\% 69$, pelviste $\% 41$, femurda $\% 25$, üst ekstremitelerlerde \%15, kraniyumda \%14 olarak bulunmuştur. Klinisyene başvurunun en sık nedenleri kanser hikâyesi olmayan hastalarda kemik ağrısı, kırılmak üzere olan metastatik lezyon ya da patolojik kırıktır. Önerilen radyolojik çalışmalar; röntgen, manyetik rezonans (MR) görüntüleme, bilgisayarlı tomografi (BT), tüm vücut kemik sintigrafisi (TVKS) ve gerektiğinde pozitron emisyon tomografidir (PET). Metastatik tümör olguları çoğunlukla bir biyopsi tanısı gerektirir. Uzun kemik metastatik lezyonlarının ya da patolojik kırıklarının cerrahi tedavisi intramedüller çivi, plak, megaprotez gibi implantlar ve çimento ile yapılmaktadır. Femurun diyafizer lezyonlarında genellikle intramedüller çiviler tercih edilmektedir. Humerus diyafizer lezyonlarda intramedüller çivi ve plaklar, tibiada intramedüller çivi, önkolda plaklar ön planda yer almaktadır. Metastatik lezyon cerrahi tedavisinde çimento, kemik defektlerini doldurmada ve stabiliteyi artırmada kullanılan önemli bir dolgu malzemesidir.
\end{abstract}

Anahtar sözcükler: kemik doku tümörleri; tümör metastazı; diyafiz; patolojik kırık; kemik çivileri
A common location for distant relapses of many cancers, including breast, lung and prostate cancer, is bone tissue. Life expectancy is reduced in patients with malignant tumours with bone metastases. Percentages of metastatic involvement of vertebrae, pelvis, femur, upper extremity and cranium are $69 \%, 41 \%, 25 \%, 15 \%$ and $14 \%$, respectively. The most common reasons for referral to a clinician are bone pain in patients without a history of cancer, a metastatic lesion on the verge of a fracture and pathological fracture. The recommended radiological investigations include $x$-ray, magnetic resonance imaging, computerized tomography, bone scan and positron emission tomography when necessary. Metastatic tumors often require a biopsy for a diagnosis. The surgical treatment of long bone metastatic lesions or pathological fractures is accomplished by implants such as intramedullary nail, plate, megaprostheses and cement. In femur diaphyseal lesions, intramedullary nails are usually preferred. Intramedullary nails and plates in humerus diafizer lesions, intramedullary nails in tibia, plates in forearm lesions are in the front line. In surgical treatment of metastatic lesions, cement is a significant filling material for bone defects and improving stability of the bone.

Key words: bone tissue neoplasms; neoplasm metastasis; diaphysis; pathological fracture; bone nails

\section{KEMIK METASTAZLARI}

Kemik, akciğer ve karaciğerden sonra en sık metastaz olan üçüncü dokudur. Diğer yandan, kemik metastazları kemik dokunun en sık görülen malign tümörüdür.

Kemik metastazları sıklıkla prostat (\%34), meme (\%22) ve akciğer (\%20) tümörlerinden kaynaklanır. ${ }^{[1]}$ Kemik metastazları daha az sıklıkta tiroid kanseri, böbrek hücreli kanser, kolon kanseri, pankreatik kanserler, melanoma, diğer ürolojik maligniteler, diğer kemik tümörleri ve yumuşak doku sarkomlarında görülmüştür. ${ }^{[2-5]}$ Kemik metastazı olduktan sonraki beklenen yaşam süreleri; melanomada 6 ay, akciğer kanserinde 6-7 ay, mesane kanserinde 6-9 ay, böbrek hücreli kanserde 12 ay, prostat kanserinde 12-53 ay, meme kanserinde $19-25$ ay ve tiroid kanserinde 48 aydır. ${ }^{[6]}$ Metastatik tutulum oranları vertebrada $\% 69$, pelviste $\% 41$, femurda $\% 25$, üst ekstremitelerlerde $\% 15$, kraniyumda $\% 14$ olarak bulunmuştur.

- İletişim adresi: Dr. Mustafa Onur Karaca, Ankara Üniversitesi Tıp Fakültesi İbni Sina Hastanesi, 6. Kat Ortopedi ve Travmatoloji Kliniği, Sıhhiye, Altındağ, Ankara Tel: 0312 - 5082696 e-posta: onurkaraca@ankara.edu.tr

- Geliş tarihi: 16 Ağustos 2019 Kabul tarihi: 22 Ekim 2019 


\section{Klinik Seyir}

Hastaların ortopedi ve travmatoloji uzmanına başvurmalarının en sık nedeni, kanser öyküsü olmayan hastalarda kemik ağrısı ya da patolojik kırıktır. Primer karsinom öyküsü olan hastalarda semptom genellikle kemik ağrısıdır. Diğerleri kanser evreleme çalışmalarında ortaya çıkar. Kemik ağrısı künt, keskin, yayılıcı, aralıklı gibi çok çeşitli olmakla beraber, genelde kemirici tarzda ve gece ağrısı şeklindedir. Çevre dokulara metastaz, ağrının karakterini ve şiddetini değiştirebilir. Yük verme ile ağıı oluşması patolojik kırık riskini ortaya koyar. Hu ve ark., kemik metastazlarına bağlı patolojik kırık oluşumunun \%75'inin travma olmaksızın günlük aktiviteler sırasında ya da kendiliğinden oluştuğunu göstermişlerdir. ${ }^{[7]}$ Primer sarkom ve enfeksiyonların da aynı tablo ile hekime başvurabileceği akılda tutulmalıdır.

Kemik metastazları sıkça omurga, pelvis, omuz kuşağı ve proksimal femur bölgelerini tutar. ${ }^{[8]}$ Akciğer kanseri dışında, diz ve dirsek distaline metastaz sık görülmez. ${ }^{[9]}$

\section{Görüntüleme}

Lezyonu doğru değerlendirmek için iki yönlü ve tüm kemiği içeren grafiler çekilmelidir. Lizis veya matrikste yoğunluk, kortikal devamsızlık, periosteal reaksiyon, çevre yumuşak dokuya yayılım ve birçok bölgede lezyon olması, metastatik lezyon veya patolojik kırık düşündürür. ${ }^{[10]}$

Bir santimetreye kadar lezyonlar ve \%50'den az trabeküler kemik yıkımı radyografide tespit edilemeyebilir. Medüller lezyonlar kortikal lezyonlara göre daha geç dönemde radyografik bulgu verir. Bu nedenle, kemik yıkımı, tümör büyüklüğü, kırık riski ve implant seçimi açısından, bilgisayarlı tomografi (BT) ve manyetik rezonans (MR) görüntüleme önemlidir. BT, metastazdaki kortikal kemik yıkımını, sklerotik değişiklikleri, yumuşak dokuya uzanımı görme ve biyopside kullanılması açılarından değerliyken; MR, kemik iliğini gösterebilme, cerrahi ve ışın tedavisini planlamada üstündür. Tüm vücut kemik sintigrafisi (TVKS), metastatik diğer odakları araştırmak açısından önemlidir. Ancak, TVKS'nin duyarlılığı yüksek olmasına rağmen özgüllüğü düşüktür. Travmatik, inflamatuvar ve tümöral bütün süreçler sonuca dâhil olur. Hızlı ilerleyen miyelom gibi osteolitik lezyonlarda pozitif sonuç vermeyebilir. Radyografiden 2-18 ay önce kemikteki malign kemik lezyonlarını tespit edebilir. ${ }^{[11]}$

\section{Biyopsi}

Kemik metastazları tanısında standart yaklaşım; klinik, laboratuvar ve görüntüleme ile tanı koyulamıyorsa yani primer bilinmiyorsa veya lezyon soliter ise biyopsi yapmaktır. Tümör, primer kemik sarkomu veya sekonder primer bir sarkom olabilir.

\section{Tedavi}

Her bir lezyon için multidisipliner bir yaklaşımla; analjezi, radyoterapi, sistemik tedavi (hormonal, kemoterapi, bisfosfonat), minimal invaziv tedavi (radyofrekans ablasyon, termoablasyon, kriyoterapi, sementoplasti, MR kılavuzlu ultrason tedavisi, embolizasyon, alkolizasyon) veya ortopedik cerrahi tedavi kararları verilmelidir. ${ }^{[12]}$ Birden çok lezyonu olan hastalar radyofarmasötik tedavi için adaydır. ${ }^{[13]}$ Kırığa yatkın metastazları kırık olmadan fikse etmek daha az cerrahi kanama, hastanede daha az kalış süresi, daha iyi fonksiyon ve uzun hayatta kalım ile ilişkilidir. ${ }^{[14,15]}$

Böbrek ve tiroid kanserleri kaynaklı metastazlar ileri derece vaskülarizedir ve kanamaya eğilimlidir. Bu nedenle, cerrahiden veya biyopsiden 24-48 saat önce embolizasyon planlanmalıdır.

Metastatik kırıklı hastalarda profilaktik antibiyotik tedavisi için ikinci jenerasyon sefalosporin ajan 24 saat boyunca verilebilir. Hastanın daha önce hastanede yatış veya dirençli mikroorganizma öyküsü mevcut ise vankomisin verilebilir.

Metastatik kırıklar, özellikle de akciğer kaynaklı olanlar, yüksek tromboz riski ile ilişkilidir; bu nedenle, profilaktik antitrombotik tedavi düzenlenmelidir. ${ }^{[16]}$

Hastaların hayatta kalma süreleri kısa olması nedeniyle, cerrahi sonrası ekstremitenin bir an önce günlük hayata uygun şekilde fonksiyonellik kazanması ve üstüne yük verilebilir hale gelmesi önemlidir. ${ }^{[17]} \mathrm{Bu}$ yüzden; tedavi planı içerisinde kemik iyileşmesi, allogreft kaynaması, stem veya kapların yüzeylerine kemik doku ilerlemesi gibi normal iyileşme prosedürleri daha az olmalı, bunun yerine çimentolu implantlar tercih edilmelidir. Çimentolama; düşük viskoziteli ve minimal basınçlı olmalı, temiz yüzeylere yapılmalı ve hastada yağ embolisine neden olmamak için uygun hidrasyon eşliğinde uygulanmalıdır.

Profilaktik tespitin ilgili kemiğin tamamına uygulanması klasik öğretidir. İntramedüller çivi veya eklem çevresi plaklar ile profilaktik tespit yapılabilir. Bu konuda görüş birliği endike ise intramedüller çivinin kemiğin tamamını kapsayacak şekilde en geniş çap ve uzunlukta yerleştirilmesidir. ${ }^{[18]}$ Intramedüller oyma işleminin akciğere metastatik yayılım yaptığına dair kanıt yoktur. Bu nedenle çivi implantasyonundan önce oyma işlemi yapılabilir. ${ }^{[19]}$ Kullanılacak çivi, kilitli çivi olmalıdır (Şekil 1).

Geniş bir kemik defekt mevcut ise ya da kırık kaynaması öngörülmüyorsa en iyi çözüm plak veya çivi ile kombine çimento uygulamasıdır. Lezyonun küretajı mutlaka yapılmalıdır. Sonrasında kırık plak üstünde redükte edilip bir veya iki vida ile stabilize edilir. Kanal 


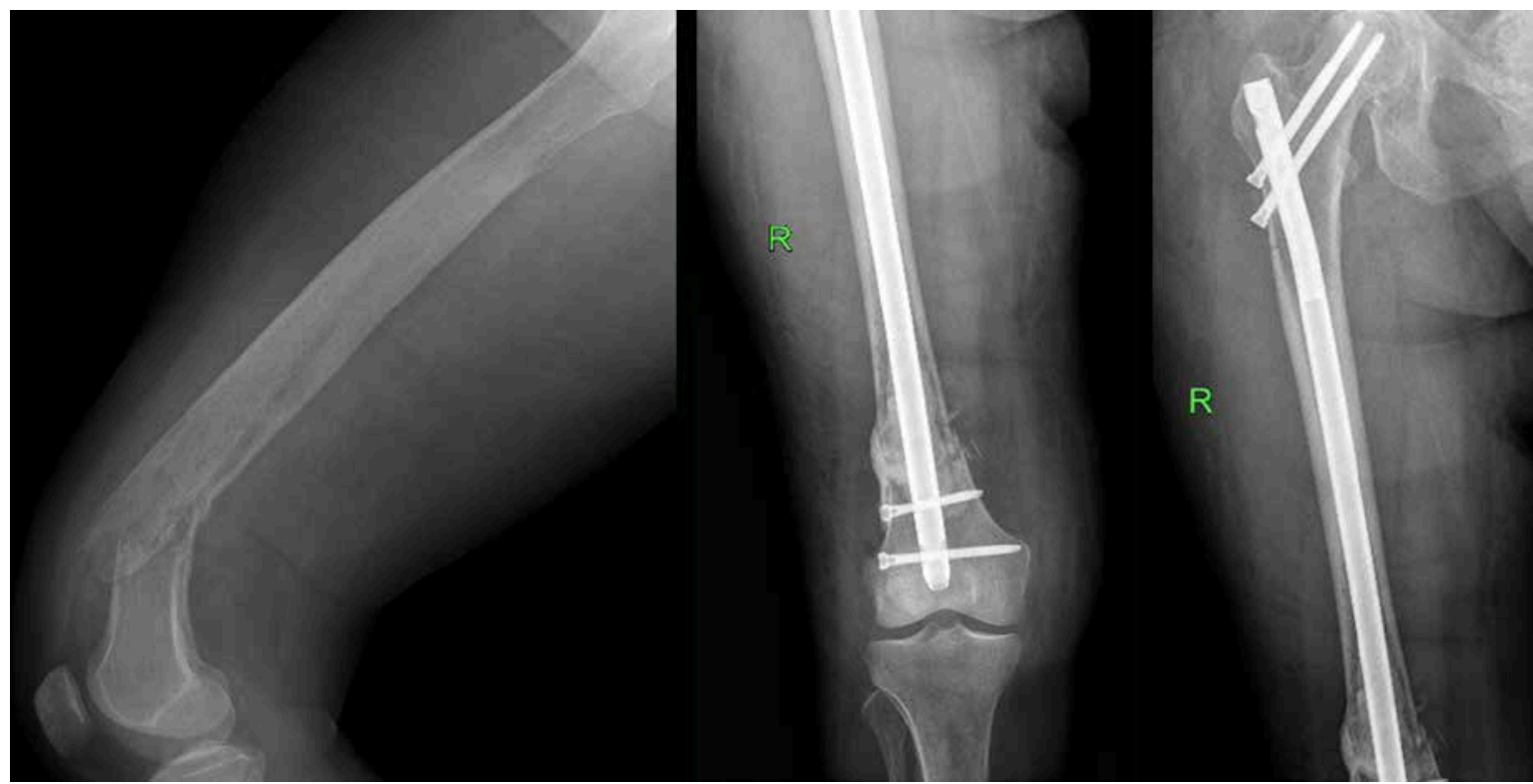

Şekil 1. Non-Hodgkin lenfoma olgusunda femur proksimal subtrokanterik bölgede metastatik tutulum ve distalde patolojik kırık. Tedavi için boyuna vida göndermeye izin veren çivi ve distalde kırıkbölgesinde kilitli vida - çimento kullanılması/uygulanması.

içine ve defektli bölgeye tercihen antibiyotikli çimento uygulamasıyla birlikte çivi veya plak ile yeterli tespit uygulanmalıdır. Çoklu lezyonlarda, çivi ve plağın ikisi birden aynı kemiğe uygulanabilir (Şekil 2).
Çimentoya anti-kanser ajan eklenmesi de başka bir seçenektir. Paket başına 100-150 mg metotreksat ilavesi yapılır. Operasyonu takiben üçüncü günde folik asit enjeksiyonu yapılmalıdır. Ameliyat sonrası

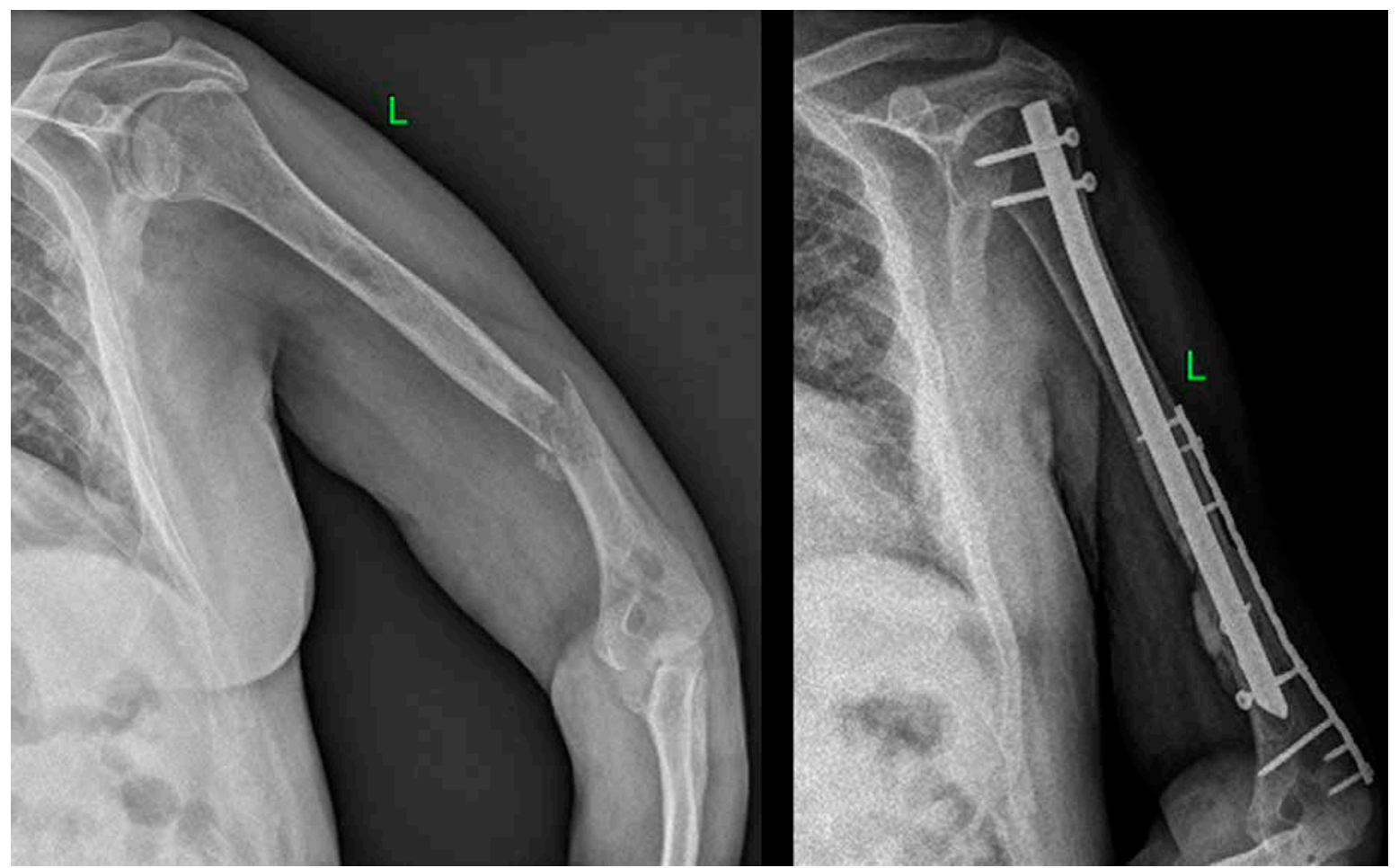

Şekil 2. Humerusta metastatik böbrek hücreli kanser olgusunda çivi, plak ve çimentonun birlikte kullanımı. 


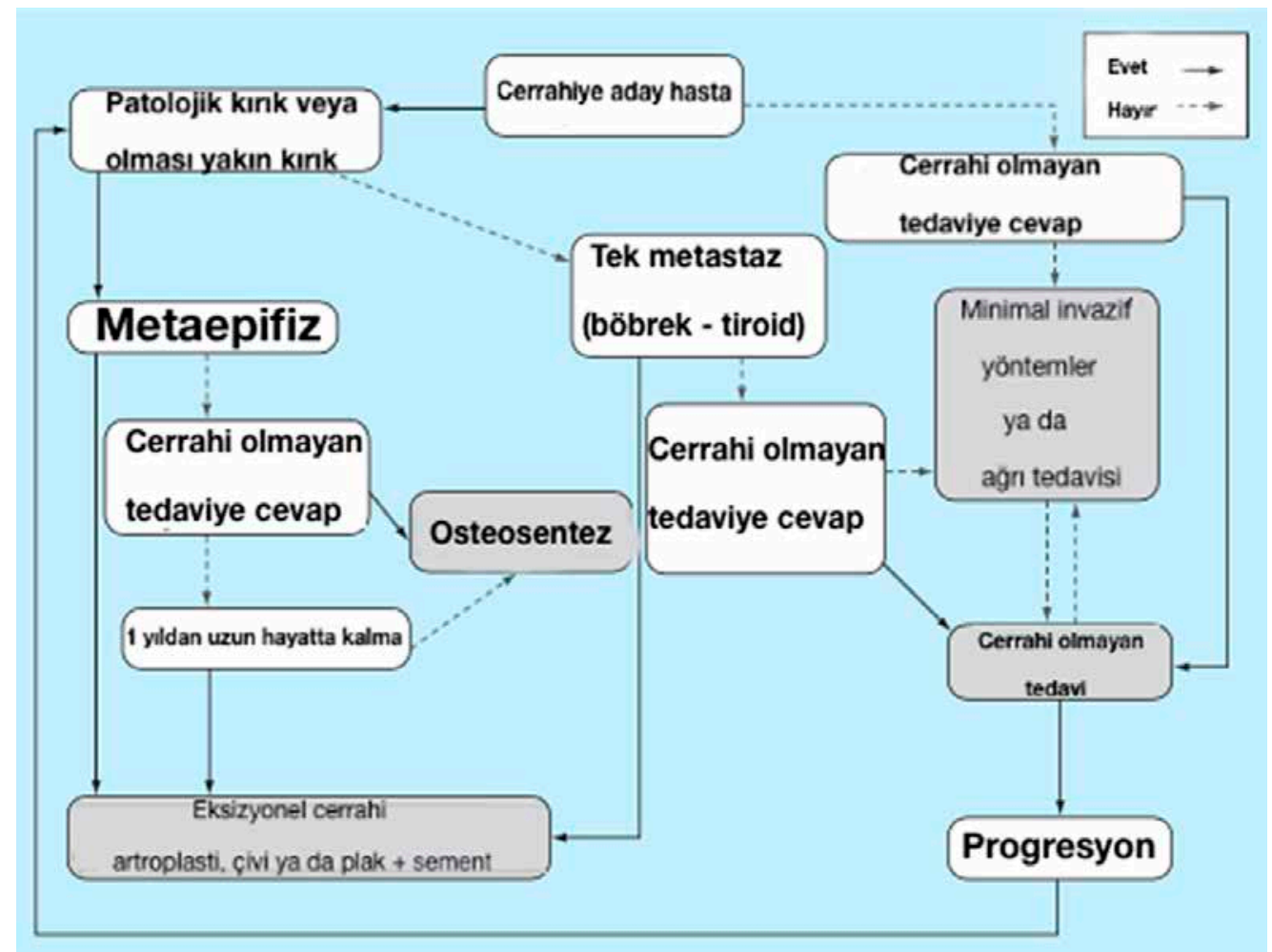

Şekil 3. Uzun kemik metastazlarında tedavi şeması. ${ }^{[21]}$

radyoterapinin etkisini artırabilen sisplatin, paket başına 200 mg'a kadar kullanılabilir. Bu durumda böbrek fonksiyonları takip edilmelidir. ${ }^{[20]}$

Açık küretaj yapılıp yapılmaması ameliyattan önce değerlendirilmelidir. Açık küretajın avantajları, anatomik bölgedeki tümör dokusunun azaltılarak radyoterapiye cevabın artırılması ve tespit kalitesinin çimento ile güçlendirilerek hastanın erken fonksiyon kazanabilmesidir. Dezavantajları ise uzun ameliyat süresi ve kan kaybı ile cerrahi risklerin artmasıdır. Uzun kemik metastazlarında tedavi şeması Şekil 3'te özetlenmiştir.[21]

Cerrahi sonrası radyoterapi, nüksü engellemek açısından yararlıdır. Townsend ve ark., radyoterapiden sonra lokal nüksün \%15'ten \%3'e düştüğünü göstermişlerdir. ${ }^{[22]}$ Fraksiyon sayısı azaltılmış radyoterapi rejimi toplam dozu daha kısa sürede vermek için kullanılır. Radyoterapiye yanıt verme, meme ve prostat kanserlerinde akciğer ve böbrek kanserlerine göre daha iyidir. Tedavinin başlangıcında ağrılar artabilir. Metalik implant varlığı radyoterapiye engel değildir. Radyasyonun, kemik iyileşmesini ve proteze kemik ilerlemesini duraklattığını unutmamak gerekir. Radyoterapinin, eğer mümkünse, intramedüller çivinin tamamını kapsayacak şekilde verilmesi gerekir. ${ }^{[12]}$

\section{ANATOMIK BÖLGELERE GÖRE CERRAHI TEDAVi}

\section{Femur}

Femur diyafiz lezyonları en iyi bütün femuru içine alan intramedüller çiviler ile tedavi edilir. Çelik çivilere göre daha ince ve güçlü olmaları nedeniyle, titanyum çiviler tercih edilir. Femur için çivi kullanımında, boyuna mutlaka vida gönderilerek bu bölge ileride oluşabilecek bir kırığa karşı güvenceye alınmalıdır (Şekil 1). ${ }^{[19,23]}$ Metastatik doku çivi giriş noktasına yakın ise bu bölgeden medullaya doğru çimento enjekte edilerek yapı güçlendirilebilir.

Femur başında veya boynunda hastalık olmadığına ve bu bölgede vida komplikasyonlarına yol açmayacak yeterli kemik stoğu olduğuna emin olmak gerekir. Bu gibi durumlarda, kalkar destekli ya da megaprotezler kullanılmalıdır. ${ }^{[24]}$ Tek lezyonlarda rezeksiyon sonrası diyafiz interkalar protez, çivi-sement kombinasyonu ya da oto-allogreft ile rekonstrüksiyon, cerrahi seçeneklerdir.

Distal femur şaft veya metafizer metastazlı olguların adjuvan tedavilerinde, tümör duyarlılığı ve hastanın genel durumu tedaviyi şekillendirir. Hayat beklentisi kısa olan hastalarda, kilitli plak ve çimento ile palyatif bir 


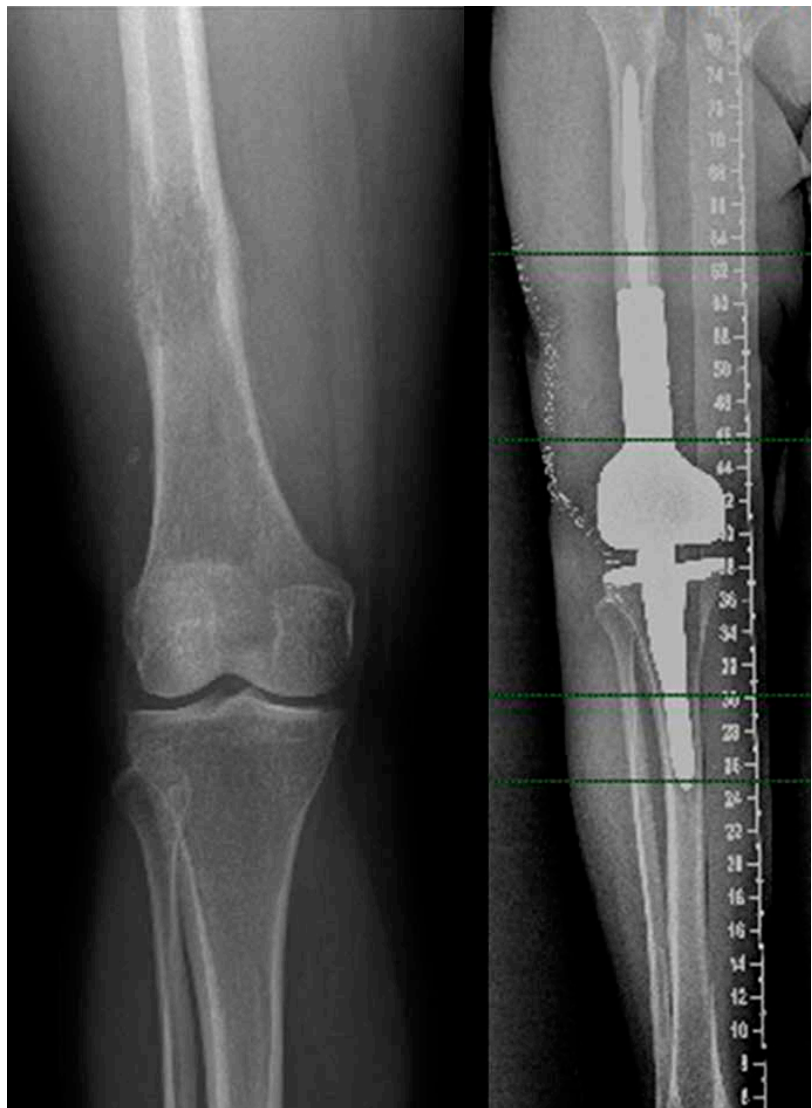

Şekil 4. Distal femur diyafizer bölgedeki metastatik soliter akciğer kanseri lezyonu distal femur rezeksiyon protezi ile rekonstrükte edilmiş. tedavi uygun olacaktır. Diğer durumlarda, masif rezeksiyon protezi, erken tam yük verebilme ve iyi fonksiyonel sonuçlar ortaya koyacaktır (Şekil 4). ${ }^{[21]}$

\section{Humerus}

Humerus diyafizer bölge lezyonları için çivi uygulaması çimentolu veya çimentosuz yapılabilir. Plak ile birlikte çimento uygulaması bir diğer seçenektir. ${ }^{[25]}$ Ekstremitede kısalma, fonksiyon üstüne olumsuz etki yapmaz. ${ }^{26]}$

Metastaz metafize ve ekleme uzanıyorsa ters omuz mobilitesi sunan bir rezeksiyon protezi kullanılabilir. ${ }^{[27]}$ Diyafizer lezyonlarda çivi ve/veya plak, çimento ile veya çimentosuz uygulanabilir. Distal lezyonlarda dirsek protezi yapılabilir (Şekil 5).

\section{Tibia}

Tibia metastazları nadir olmakla birlikte, tedavileri femur ve humerustaki lezyonlara benzerdir. Geniş kemik kaybı ile birlikte olan eklem çevresi destrüksiyonları masif protez gerektirebilir. ${ }^{[28]}$ Diyafizer lezyonlarda, tüm kemiği kapsayan kilitli çiviler kullanılabilir. Distal lezyonlarda, kilitli plaklarla kombine sement kullanılabilir. Eklem çevresi lezyonlarda veya patolojik kırıklar$\mathrm{da}$, amputasyon seçeneği hasta ile konuşulmalıdır.

Patolojik kırık riski durumunda ve patolojik kırık sonrası anatomik bölgeye göre kullanılacak cerrahi seçenekler Tablo 1'de özetlenmiştir.

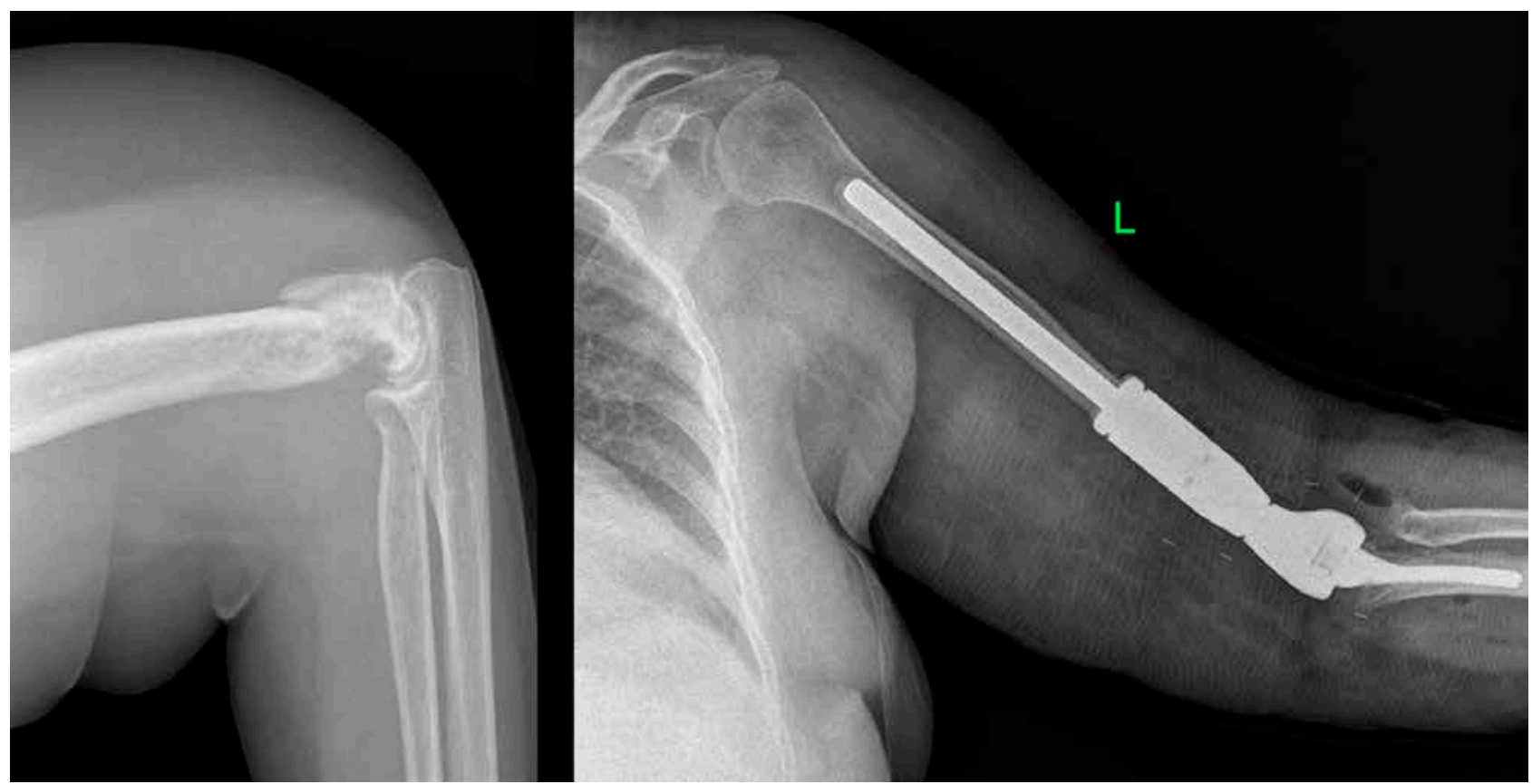

Şekil 5. Meme kanseri olgusunda humerus distalindeki metastatik lezyon dirsek protezi ile rekonstrükte edilmiş. 
Tablo 1. Patolojik kırık riski durumu ve patolojik kırık sonrası anatomik bölgeye göre önerilen cerrahi tedaviler[12]

\begin{tabular}{|c|c|c|c|}
\hline & Anatomik Bölge & Patolojik kırık öncesi tedavi & Patolojik kırık sonrası tedavi \\
\hline \multirow[t]{3}{*}{ Humerus } & Proksimal & Prok. humerus plağı, iMÇ & Artrop. veya çimentolu plak \\
\hline & Diyafizer & IMÇ & iMÇ ve çimento \\
\hline & Distal & Distal humerus plağı & Total dirsek artrop. veya çimentolu distal humerus plağı \\
\hline \multirow[t]{3}{*}{ Radius } & Proksimal & T plağı, radius başı artrop. & Çimento ile T plağı, radius başı artrop. \\
\hline & Diyafizer & Plak veya elastik çivi & Çimento ile plak veya elastik çivi \\
\hline & Distal & Distal radius plağı & Çimento ile distal radius plağı veya ulna el bileği artrodezi \\
\hline \multirow[t]{3}{*}{ Ulna } & Proksimal & Olekranon plağı & Çimento ile olekranon plağı veya TDA \\
\hline & Diyafizer & Plak veya elastik çivi & Çimento ile plak veya elastik çivi \\
\hline & Distal & Plak & Çimento ile plak veya rezeksiyon \\
\hline \multirow[t]{3}{*}{ Femur } & Proksimal & IMÇ, çimentolu artrop. & Çimento ile IMÇ veya rezeksiyon artrop. \\
\hline & Diyafizer & IMÇ & Çimento ile IMÇ \\
\hline & Distal & DFP veya retrograd çivi & Çimento ile DFP veya rezeksiyon artrop. \\
\hline \multirow[t]{3}{*}{ Tibia } & Proksimal & PTP & Çimento ile PTP veya rezeksiyon artrop. \\
\hline & Diyafizer & iMç & Çimento ile IMÇ \\
\hline & Distal & Distal tibia plağı & Çimento ile distal tibia plağı veya amputasyon \\
\hline \multirow[t]{3}{*}{ Fibula } & Proksimal & Cerrahiye gerek yok & Cerrahiye gerek yok \\
\hline & Diyafizer & Cerrahiye gerek yok & Cerrahiye gerek yok \\
\hline & Distal & DFiP veya retrograd vida & Distal fibula plağı veya ayak bileği artrodez \\
\hline
\end{tabular}

iMÇ, intramedüller çivi; prok, proksimal; artrop, artroplasti; DFP, distal femur plağı; PTP, proksimal tibia plağı; DFiP, distal fibula plağı; TDA, total dirsek artroplastisi.

\section{KAYNAKLAR}

1. Svensson E, Christiansen CF, Ulrichsen SP, Rørth MR, Sørensen HT. Survival after bone metastasis by primary cancer type: a Danish population-based cohort study. BMJ Open 2017;7(9):e016022. Crossref

2. Baek S-J, Hur H, Min B-S, Baik S-H, Lee K-Y, Kim N-K. The Characteristics of Bone Metastasis in Patients with Colorectal Cancer: A Long-Term Report from a Single Institution. World J Surg 2016;40(4):982-6. Crossref

3. Borad MJ, Saadati H, Lakshmipathy A, Campbell E, Hopper $P$, Jameson G, Von Hoff DD, Saif MW. Skeletal metastases in pancreatic cancer: a retrospective study and review of the literature. Yale J Biol Med 2009;82(1):1-6. Erişim: https:// www.ncbi.nlm.nih.gov/pmc/articles/PMC2660584/

4. Fukutomi $M$, Yokota $M$, Chuman $H$, Harada $H$, Zaitsu $Y$, Funakoshi A, Wakasugi $H$, Iguchi $H$. Increased incidence of bone metastases in hepatocellular carcinoma. Eur J Gastroenterol Hepatol 2001;13(9):1083-8. Crossref

5. Alva A, Davis E, Chinnaiyan AM, Dhanasekaran S, Mehra R. Urothelial Cancer with Occult Bone Marrow Metastases and Isolated Thrombocytopenia. Urol Case Reports 2015;3(4):98-100. Crossref

6. Selvaggi G, Scagliotti GV. Management of bone metastases in cancer: A review. Crit Rev Oncol Hematol 2005;56(3):36578. Crossref

7. Hu YC, Lun DX, Wang $\mathrm{H}$. Clinical features of neoplastic pathological fracture in long bones. Chin Med J (Engl) 2012;125(17):3127-32.

8. Coleman RE. Clinical Features of Metastatic Bone Disease and Risk of Skeletal Morbidity. Clin Cancer Res 2006;12(20):6243s-9s. Crossref
9. HealeyJH, Turnbull AD, Miedema B, Lane JM. Acrometastases. A study of twenty-nine patients with osseous involvement of the hands and feet. J Bone Joint Surg Am 1986;68(5):743-6. Crossref

10. Janssen SJ, van der Heijden AS, van Dijke M, Ready JE, Raskin KA, Ferrone ML, Hornicek FJ, Schwab JH. 2015 Marshall Urist Young Investigator Award: Prognostication in Patients with Long Bone Metastases: Does a Boosting Algorithm Improve Survival Estimates? Clin Orthop Relat Res 2015;473(10):3112-21. Crossref

11. Even-Sapir E. Imaging of malignant bone involvement by morphologic, scintigraphic, and hybrid modalities. J Nucl Med 2005;46(8):1356-67. Erişim: http://jnm.snmjournals. org/content/46/8/1356.long

12. Capanna R, Piccioli A, Di Martino A, Daolio PA, Ippolito V, Maccauro G, Piana R, Ruggieri P, Gasbarrini A, Spinelli MS, Campanacci DA; The Italian Orthopaedic Society Bone Metastasis Study Group. Management of long bone metastases: recommendations from the Italian Orthopaedic Society bone metastasis study group. Expert Rev Anticancer Ther 2014;14(10):1127-34. Crossref

13. Petersen LJ, Lund L, Jønler $M$, Jakobsen $M$, Abrahamsen J. Samarium-153 treatment of bone pain in patients with metastatic prostate cancer. Dan Med Bull 2010;57(6):A4154.

14. Ward WG, Holsenbeck S, Dorey FJ, Spang J, Howe D. Metastatic disease of the femur: surgical treatment. Clin Orthop Relat Res 2003;415(Suppl):S230-44. Crossref

15. Katzer A, Meenen N, Grabbe F, Rueger J. Surgery of skeletal metastases. Arch Orthop Trauma Surg 2002;122(5):251-8. Crossref 
16. Shallop B, Starks A, Greenbaum S, Geller DS, Lee A, Ready J, Merli G, Maltenfort M, Abraham JA. Thromboembolism After Intramedullary Nailing for Metastatic Bone Lesions. J Bone Joint Surg Am 2015;97(18):1503-11. Crossref

17. Eastley N, Newey M, Ashford RU. Skeletal metastases - The role of the orthopaedic and spinal surgeon. Surg Oncol 2012;21(3):216-22. Crossref

18. Rossi B, Scaramuzzo L, Spinelli MS, Yang Z, Maccauro G. Intramedullary nailing for treatment of pathologic femoral fractures due to metastases. Injury 2014;45(2):412-7. Crossref

19. Arvinius C, Parra JLC, Mateo LS, Maroto RG, Borrego AF, Stern LL-D. Benefits of early intramedullary nailing in femoral metastases. Int Orthop 2014;38(1):129-32. Crossref

20. Anract $P$, Biau D, Boudou-Rouquette P. Metastatic fractures of long limb bones. Orthop Traumatol Surg Res 2017;103(1):S41-51. Crossref

21. Townsend PW, Rosenthal HG, Smalley SR, Cozad SC, Hassanein RE. Impact of postoperative radiation therapy and other perioperative factors on outcome after orthopedic stabilization of impending or pathologic fractures due to metastatic disease. J Clin Oncol 1994;12(11):2345-50. Crossref

22. Cheung FH. The Practicing Orthopedic Surgeon's Guide to Managing Long Bone Metastases. Orthop Clin North Am 2014;45(1):109-19. Crossref
23. Choy W-S, Kim KJ, Lee SK, Yang DS, Jeung SW, Choi HG, Park HJ. Surgical Treatment of Pathological Fractures Occurring at the Proximal Femur. Yonsei Med J 2015;56(2):460. Crossref

24. Wedin R, Bauer HCF. Surgical treatment of skeletal metastatic lesions of the proximal femur. J Bone Joint Surg Br 2005;87$B(12): 1653-7$. Crossref

25. Laitinen $M$, Nieminen J, Pakarinen T-K. Treatment of pathological humerus shaft fractures with intramedullary nails with or without cement fixation. Arch Orthop Trauma Surg 2011;131(4):503-8. Crossref

26. Schwabe P, Ruppert M, Tsitsilonis S, Melcher I, Schaser K-D, Märdian S. Surgical management and outcome of skeletal metastatic disease of the humerus. Acta Chir Orthop Traumatol Cech 2014;81(6):365-70.

27. Kassab M, Dumaine V, Babinet A, Ouaknine M, Tomeno $B$, Anract P. Twenty nine shoulder reconstructions after resection of the proximal humerus for neoplasm with mean 7-year follow-up. Rev Chir Orthop Reparatrice Appar Mot 2005;91(1):15-23.

28. Kelly CM, Wilkins RM, Eckardt JJ, Ward WG. Treatment of metastatic disease of the tibia. Clin Orthop Relat Res 2003;(415 Suppl):S219-29. Crossref 